\title{
Índices fisiológicos de girassol em consórcio com forrageiras no Sistema Integração Lavoura-Pecuária
}

\section{Physiological indices of sunflower in consortium with forage in the Integrated Crop-Livestock System}

Jamile Maria da Silva dos Santos ${ }^{1}$, Clovis Pereira Peixoto ${ }^{1}$, Ademir Trindade Almeida ${ }^{1}$, Ellen

Rayssa Oliveira $^{1 *}$, Elvis Lima Vieira ${ }^{1}$, Valfredo da Silva Pereira ${ }^{1}$

\begin{abstract}
RESUMO
Objetivou-se avaliar o crescimento e o desenvolvimento do girassol em consórcio com forrageiras no sistema integração lavoura-pecuária. Utilizou-se o delineamento experimental de blocos casualizados em esquema fatorial $3 \times 3+1$. Os tratamentos foram constituídos de três consórcios do girassol com as forrageiras (girassol + Urochloa ruziziensis, girassol + Panicum maximum cv. Tanzânia, girassol + Urochloa ruziziensis + Cajanus cajan), semeados de três formas diferentes (simultânea, defasada e simultânea com aplicação de herbicida/graminicida) e o girassol solteiro como testemunha em quatro repetições estudados em três anos agrícolas. Foram determinados os índices fisiológicos taxa de crescimento relativo (TCR), taxa asimilatória líquida (TAL), razão de área foliar (RAF), índice de área foliar (IAF) e taxa de crescimento da cultura (TCC). Os dados foram submetidos a análise de variância e ajustados por equação polinomial de segundo grau, representando o crescimento em função do tempo com o programa TableCurve. Os índices TAL, IAF e TCC indicam os consórcios girassol + Urochloa ruziziensis e girassol + Urochloa ruziziensis + Cajanus cajan como os que apresentam melhor desempenho do girassol.
\end{abstract}

Palavras-chave: Helianthus annuus L.; Análise de crescimento; Plantio direto.

\section{ABSTRACT}

The objective was to evaluate the growth and development of sunflower in consortium with forages in the integrated crop-livestock system. A randomized block experimental design was used in a $3 \times 3+1$ factorial scheme. The treatments consisted of three intercropping of sunflower with forages (sunflower + Urochloa ruziziensis, sunflower + Panicum maximum cv. Tanzânia, sunflower + Urochloa ruziziensis + Cajanus cajan), sown in three different ways (simultaneous, lagged and simultaneous with herbicide application). (graminicide) and single sunflower as a control in four replications studied in three crop years. Physiological indices relative growth rate (RCR), net assimilation rate (TAL), leaf area ratio (RAF), leaf area index (LAI) and crop growth rate (TCC) were determined. The data were submitted to analysis of variance and adjusted by polynomial equation of second degree, representing the growth in function of the time with the program TableCurve. The TAL, IAF and TCC indices indicate the sunflower + Urochloa ruziziensis and sunflower + Urochloa ruziziensis + Cajanus cajan intercrops as the ones with the best sunflower performance.

Keywords: Helianthus annuиs L.; Growth analysis; No-till.

\footnotetext{
${ }^{1}$ Universidade Federal do Recôncavo da Bahia

*E-mail: ellen.rayoli@ufrb.edu.br
} 


\section{INTRODUÇÃO}

A evolução tecnológica de produção levou a uma caracterização da atividade agrícola com tendência ao monocultivo, o qual predomina mundialmente nas propriedades rurais. E como consequência lógica do uso intensivo desta atividade é a ocorrência do esgotamento e degradação do solo, resistência a pragas e doenças, dentre outros fatores que levam a perda de produtividade. (MACEDO, 2009; BALBINO, et al. 2011).

Diante da realidade de degradação ambiental o sistema de produção tem que priorizar a conservação dos recursos naturais adquirindo tecnologias como o sistema plantio direto (SPD) e o sistema integração lavoura-pecuária (ILP) (MACEDO, 2009; LOSS et al., 2011).

A integração lavoura-pecuária (ILP) é um sistema que visa a diversificação do sistema produtivo em que se cultiva graníferas em associação com forrageiras destinadas à alimentação animal. Esse sistema pode ser empregado numa mesma área seja em consórcio, rotação ou sucessão de culturas (MORAES et al., 2013).

Os sistemas que integram lavoura e pecuária é o caminho para o desenvolvimento de uma agricultura ambiental e economicamente sustentável. A introdução do sistema ILP tendo por base a agricultura conservacionista e todos os benefícios do plantio direto pode proporcionar uma série de vantagens, das quais se destacam, a manutenção da fertilidade do solo, combate à erosão, melhora da estrutura do solo, ciclagem de nutrientes, controle de doenças e equilíbrio dos microorganismos do solo (GIMENES et al., 2010).

Ademais, a implementação do sistema ILP associado ao plantio direto proporciona ao solo aumentos significativos do teor de nutrientes principalmente elevados teores de matéria orgânica, quando é comparado com sistemas tradicionais. Ocorre benefícios para as características físicas, químicas e biológicas do solo, além de retenção de água, o que leva a um aumento de produtividade (COSTA et al., 2015).

As áreas de lavoura dão um bom suporte à pecuária pela produção de alimento (grão, silagem e feno) ou na oferta de pastejo. Espécies como as gramíneas se destacam por possuírem rápido crescimento e rebrota podendo ser utilizada, num primeiro momento, como forragem, e posteriormente após novo crescimento formar palhada para o SPD em safra subsequente (MACEDO, 2009).

Várias culturas têm sido utilizadas nos sistemas de ILP, entre as quais se destacam: soja, milho, milheto, sorgo, nabo forrageiro, girassol, algodão e gramíneas forrageiras tropicais, principalmente as braquiárias (Urochloa sp.)

O girassol (Helianthus annuиs L.) é uma planta que apresenta características agronômicas, físicas, químicas, organolépticas e de versatilidade que lhe confere uma excelente opção de cultivo no sistema ILP, apresentando bons resultados em cultivo com forrageiras (BRIGHENTI et al., 2008). Seu cultivo é realizado praticamente em todo o território nacional, 
uma vez que possui importante característica de adaptabilidade a condições de clima e solo, além de ser considerada uma das espécies vegetais com potencial para a produção de biodiesel.

Uma das ferramentas utilizadas para a avaliação do crescimento e desenvolvimento da planta em diferentes sistemas é a análise de crescimento, muito apropriada e bastante precisa para avaliar as bases fisiológicas da produtividade vegetal (PEIXOTO et al., 2020). A análise de crescimento é utilizada na pesquisa científica para subsidiar a avaliação do potencial de crescimento de um vegetal em resposta à variação genética, ambiental e a condições de manejo impostas (PEIXOTO et al., 2020).

Dessa forma, objetivou-se avaliar por meio dos índices fisiológicos, o crescimento e desenvolvimento do girassol em consórcio com forrageiras no sistema integração lavourapecuária.

\section{MATERIAL E MÉTODOS}

O estudo foi desenvolvido na Fazenda Experimental do Centro de Ciências Agrárias, Ambientais e Biológicas (CCAAB) da Universidade Federal do Recôncavo da Bahia (UFRB), na cidade de Cruz das Almas-BA. O local está situado a 1240'39" latitude sul e 3906'23" longitude oeste de Greenwich, com altitude de $220 \mathrm{~m}$. O clima local é tropical quente e úmido, segundo a classificação descrita por Köppen, com precipitação média anual de $1200 \mathrm{~mm}$. A temperatura média anual é de $24^{\circ} \mathrm{C}$ e umidade relativa de $80 \%$ (MENDONÇA et al., 2020). O solo é classificado como Latossolo Amarelo Distrocoeso, de textura média, relevo plano, bem drenado e profundo (SANTOS, 2013).

O delineamento experimental foi de blocos casualizados em esquema fatorial $3 \times 3+1$, três consórcios do girassol com forrageiras (girassol + Urochloa ruziziensis, girassol + Panicum maximum cv. Tanzânia e, girassol + Urochloa ruziziensis + Cajanus cajan), implantados de três formas (semeadura simultânea do consórcio, semeadura defasada do consórcio, aos 25 dias após a semeadura do girassol e, semeadura simultânea do consórcio com aplicação de herbicida/graminicida), com tratamento adicional servindo como testemunha (girassol solteiro) em quatro repetições, totalizando 40 parcelas, em três anos agrícolas.

A adubação de base na área experimental nos três anos de cultivo foi realizada no momento de abertura do sulco de semeadura com o fertilizante TOP-PHOS $280 \mathrm{HP}(\mathrm{N}=1 \%$; $\mathrm{P}_{2} \mathrm{O}_{5}=28 \% ; \mathrm{Ca}=17 \% ; \mathrm{S}=5 \%$. A adubação de cobertura foi aplicada manualmente aos $25 \mathrm{DAE}$ (dias após a emergência) do girassol com a mistura fertilizante SULFAMO META 11 ( $\mathrm{N}=15 \%$; $\mathrm{P}_{2} \mathrm{O}_{5}=3 \% ; \mathrm{K}=16 \% ; \mathrm{S}=4 \% ; \mathrm{Ca}=4 \% ; \mathrm{Cu}=0,1 ; \mathrm{Mn}=0,2 ; \mathrm{Zn}=0,3 \% ; \mathrm{B}=0,2 \%$ ) e aplicação de boro (ácido bórico) quando necessário. A quantidade de adubos utilizada foi calculada de acordo com a recomendação da cultura e os resultados das análises químicas do solo que se encontram na Tabela 1. 
Tabela 1 - Atributos químicos do solo da área experimental na camada de $0-20 \mathrm{~cm}$, nos três anos de estudo. Cruz das Almas - BA, 2020.

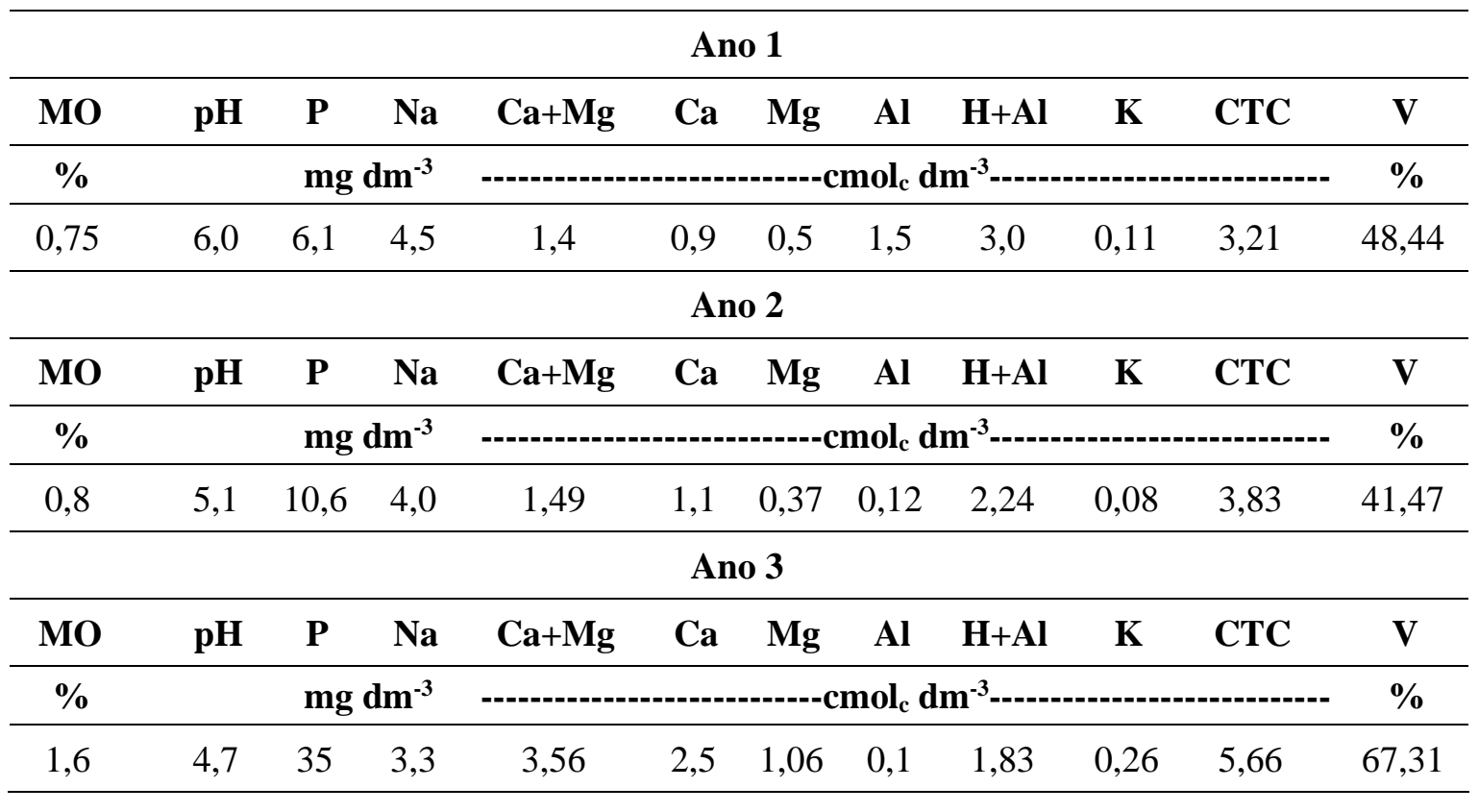

Fonte: LAGRO - Laboratório Agronômico S/C Ltda (2020).

No período da semeadura foi realizada a dessecação do capim Urochloa decumbens que serviu de palhada para a semeadura em sistema plantio direto (SPD). A semeadura do híbrido de girassol (Olisum 3) foi realizada com o auxílio de plantadeira manual tipo matraca, obedecendo o espaçamento de $0,70 \mathrm{~m}$ entre linhas de semeadura e $0,30 \mathrm{~m}$ entre plantas, com população fixa de aproximadamente 45.000 plantas ha ${ }^{-1}$ (CASTRO el al., 1996; BRIGHENTI et al., 2008). As matracas foram reguladas para depositar ao solo três sementes. Posteriormente aos 12 dias após a semeadura (DAS) do girassol foi feito o desbaste deixando apenas uma planta.

As plantas consorciadas foram semeadas manualmente nas entrelinhas do girassol, em sulcos. A quantidade de sementes utilizada a cada ano foi calculada de acordo com o valor cultural (VC) para as gramíneas (FERREIRA et al., 2007) e a porcentagem de germinação associada a recomendação para a cultura no caso da leguminosa.

Todos os tratos culturais aplicados às parcelas experimentais (cultura do girassol e plantas consorte) foram realizados seguindo as recomendações técnicas.

$\mathrm{Na}$ forma de semeadura com aplicação de herbicida foi realizada pulverização de herbicida/graminicida com o princípio ativo fluazifop-p-butyl e dosagem de $10 \mathrm{~g}$ i.a. ha ${ }^{-1}$, quando as gramíneas apresentavam 3 a 4 perfilhos, conforme Brighenti et al. (2009). A calda foi aplicada nas horas mais frescas da manhã, com auxílio de bomba costal com jato direcionado, previamente calibrado. 
As parcelas experimentais foram constituídas por oito linhas de $6,0 \mathrm{~m}$ de comprimento, mantendo fixo o espaçamento entre linhas do girassol de $0,70 \mathrm{~m}$. Destas oito linhas de plantio, três constituíram bordaduras alternadas, duas foram utilizadas para as análises de crescimento e três foram destinadas para o levantamento de dados finais, relativos aos componentes de produção da planta e a produtividade.

Nas linhas destinadas à análise de crescimento foram realizadas coletas destrutivas, nas quais eram colhidas quinzenalmente cinco plantas por parcela a partir dos $30 \mathrm{DAE}$ até a maturação plena do girassol para a determinação da massa da matéria seca total $\left(\mathrm{g} \mathrm{planta}^{-1}\right)$ e área foliar $\left(\mathrm{dm}^{2}\right)$ que serviram de base para o cálculo dos índices fisiológicos.

A massa da matéria seca total resultou da soma da massa da matéria seca das diversas frações da planta (raiz, haste, folhas, capítulo), após secarem em estufa de ventilação forçada (65 $\pm 5^{\circ} \mathrm{C}$ ), até atingirem massa constante. A área foliar foi determinada mediante a relação da massa da matéria seca das folhas e a massa da matéria seca de dez discos foliares, obtidos com o auxílio de um perfurador de área conhecida (PEIXOTO et al., 2011).

Os índices fisiológicos, taxa de crescimento relativo (TCR), taxa assimilatória líquida (TAL), taxa de crescimento da cultura (TCC), índice de área foliar (IAF) e razão de área foliar (RAF) foram calculados conforme Peixoto et al. (2011). Posteriormente, esses dados foram submetidos a análise de variância e ajustados por equação polinomial de segundo grau, representando o crescimento em função do tempo com o uso do programa TableCurve.

\section{RESULTADOS E DISCUSSÃO}

O acúmulo da massa da matéria seca e o incremento da área foliar, quantificados em função do tempo, são utilizados para estimar alguns índices fisiológicos relacionados às diferenças de desempenho entre cultivares ou diferentes materiais da mesma espécie e das comunidades vegetais, ou os diferentes manejos como os consórcios nos diversos estudos ecofisiológicos.

Os índices fisiológicos podem fornecer subsídios para o entendimento das adaptações experimentadas pelas plantas sob diferentes condições ambientais. A taxa de crescimento relativo (TCR) expressa o aumento na massa de matéria seca, partindo de uma unidade de peso inicial, em um determinado intervalo de tempo. Na Figura 1 encontram-se as curvas que representam a taxa de crescimento relativo do girassol em cultivo solteiro e em consórcio com forrageiras e nas diferentes formas de semeadura (Figura 2), ambas em três anos agrícolas.

As taxas de crescimento relativo (TCR) obtidas neste estudo possuem tendências semelhantes entre si, apresentando valores máximos no início do período vegetativo aos $30 \mathrm{DAE}$ e decrescendo com a progressão do ciclo da cultura chegando a valores negativos (Figuras 1 e 2). 
Esta variação da curva ao longo do crescimento do girassol é uma tendência natural e atribuída a diminuição do acúmulo de fitomassa pela planta que está relacionado com a redução da área foliar fotossinteticamente ativa.

Figura 1 - Taxa de crescimento relativo (TCR) em dias após a emergência (DAE) de plantas de girassol submetidas a diferentes consórcios $(\mathrm{GS}=$ girassol solteiro, $\mathrm{GB}=$ girassol + Urochloa ruziziensis (braquiária), GP=girassol + Panicum maximum cv. tanzânia, GBGu=girassol + Urochloa ruziziensis + Cajanus cajan) e formas de semeadura (A=semeadura simultânea, $\mathrm{B}=$ semeadura defasada e $\mathrm{C}=$ semeadura simultânea com aplicação de herbicida/graminicida), em três anos agrícolas. Cruz das Almas - BA, 2020.
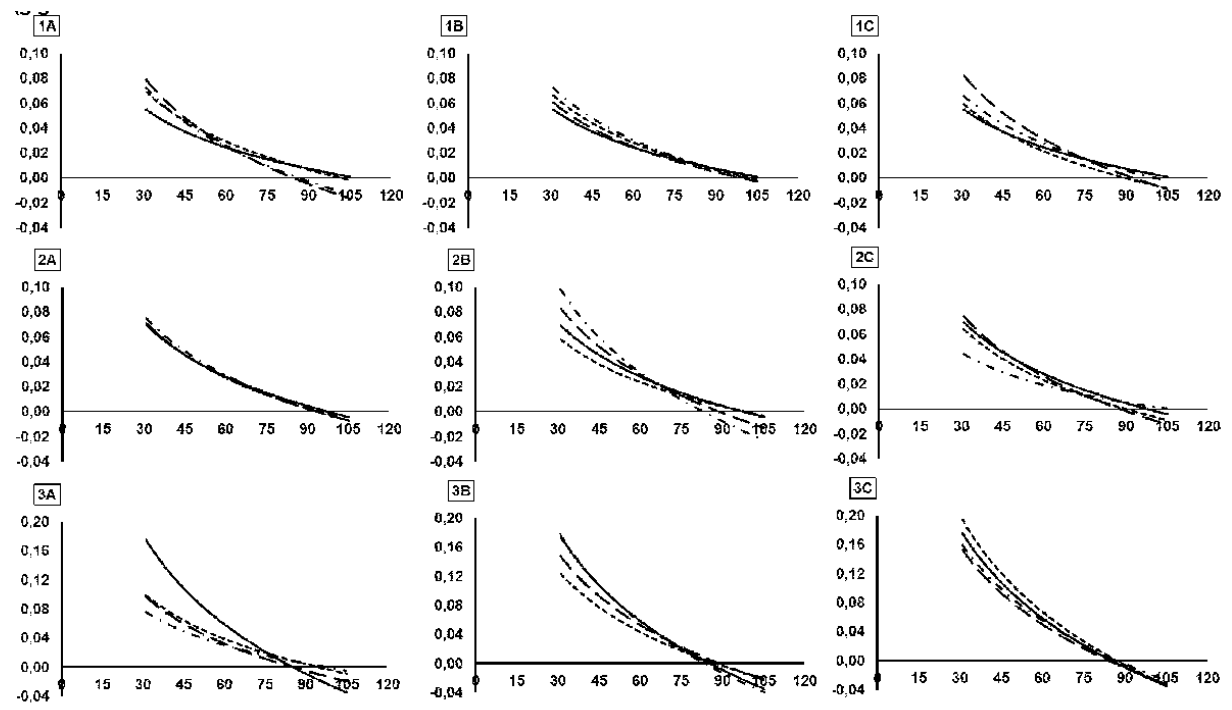

-GS - GB ---GP $-\cdot-G B G$

No primeiro ano de cultivo (Figura 1.1A, 1.1B e 1.1C) as plantas de girassol em sistema de consórcio apresentaram valores de TCR maior que em cultivo solteiro nas três formas de semeadura, equiparando-se aos 60 DAE e chegando a incrementos menores aos 90 DAE, explicado por um balanço negativo da fotossíntese/respiração, no período de enchimento dos aquênios, não havendo mais acúmulo de matéria seca pela planta. Ainda é possível observar que os consórcios GB e GBGu apresentam maiores TCR em SSH (Figura 1.1C). No terceiro ano o GS obteve valores de TCR mais elevados que os consórcios (Figura 1.3A e 1.3B).

Em alguns consórcios é possível observar que aos 90 DAE as plantas de girassol apresentaram valores negativos de TCR, enquanto outros somente aos 105 DAE, sendo bem evidente no terceiro ano de cultivo. Isso ocorre devido à senescência das folhas, predominando o processo da respiração em detrimento da fotossíntese. 
Figura 2 - Taxa de crescimento relativo (TCR) em dias após a emergência (DAE) de plantas de girassol submetidas a diferentes formas de semeaduras (semeadura simultânea, semeadura defasada e semeadura simultânea com aplicação de herbicida/graminicida) dos consórcios $(\mathrm{A}=\mathrm{GB}=$ girassol + Urochloa ruziziensis, $\mathrm{B}=\mathrm{GP}=$ girassol + Panicum maximum cv. Tanzânia e $\mathrm{C}=\mathrm{GBGu}=$ girassol + Urochloa ruziziensis + Cajanus cajan), em três anos agrícolas. Cruz das Almas - BA, 2020.

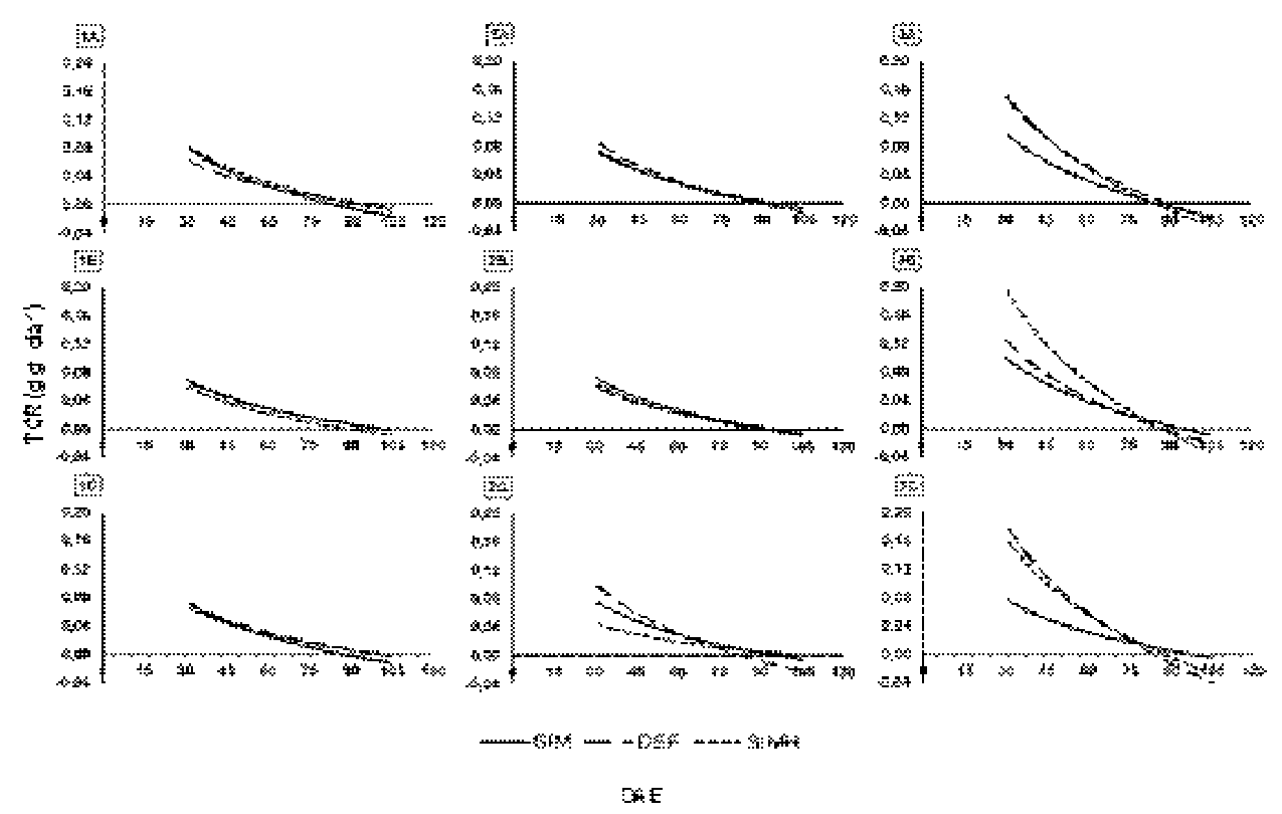

No estudo das formas de semeadura do consórcio, o girassol consorciado nos dois primeiros anos agrícolas em SS, SD e SSH apresentaram uma variação de TCR muito próxima chegando a valores negativos aos 105 DAE (Figura 2.1A, 1.B,1.C e 2.2).

No terceiro ano agrícola fica evidente que as formas de semeadura do consórcio SSH e SD implicaram em maiores TCR dos 30 aos 75 DAE atingindo valores negativos aos 90 DAE, enquanto que o girassol cultivado em SS acumulou menos matéria seca devido à concorrência interespecífica desde o início de seu desenvolvimento. Observa-se ainda, que o girassol no consórcio GP apresentou maiores valores quando aplicado a subdosagem do herbicida/graminicida, o que diminuiu a competição entre as espécies na fase de crescimento vegetativo dos 30 aos 60 DAE (Figura 2.3A, 2.3B e 2.3C).

A taxa assimilatória líquida (TAL) expressa à taxa de fotossíntese líquida ou a matéria seca produzida por unidade de área foliar por unidade de tempo. Pode ser considerada como um índice capaz de expressar o potencial da planta em armazenar os produtos gerados na fotossíntese, 
proveniente do balanço fotossintético e de tudo aquilo que é consumido na respiração e fotorrespiração, como é o caso das plantas de girassol que apresentam a rota do ciclo $\mathrm{C}_{3}$.

Nas Figuras 3 e 4 encontram-se as curvas que representam a taxa assimilatória líquida do girassol em cultivo solteiro e em consórcio com forrageiras (Figura 3) e nas diferentes formas de semeadura (Figura 4), em três anos agrícolas.

As variações da TAL mostraram um padrão definido de curvas com incremento constante até por volta do $75 \mathrm{DAE}$ para a maioria dos tratamentos e posteriormente apresentaram um declínio (Figuras 3 e 4). Esse decréscimo ocorreu devido à redução da eficiência fotossintética causada pelo autosombreamento das folhas inferiores e a presença de folhas velhas que passam a ser drenos. Além disso, a partir do 75 DAE o maior aporte dos fotoassimilados produzidos pelas plantas de girassol são requeridos para o desenvolvimento da inflorescência e posterior enchimento dos grãos, aumentando ainda mais a taxa respiratória das plantas, reduzindo a TAL.

Figura 3 - Taxa assimilatória líquida (TAL) em dias após a emergência (DAE) de plantas de girassol submetidas a diferentes consórcios (GS=girassol solteiro, GB=girassol + Urochloa ruziziensis, GP=girassol + Panicum maximum cv. Tanzânia, GBGu=girassol + Urochloa ruziziensis + Cajanus cajan $)$ e formas de semeadura $(\mathrm{A}=$ semeadura simultânea, $\mathrm{B}=$ semeadura defasada e $\mathrm{C}=$ semeadura simultânea com aplicação de herbicida/graminicida), em três anos agrícolas. Cruz das Almas - BA, 2020.
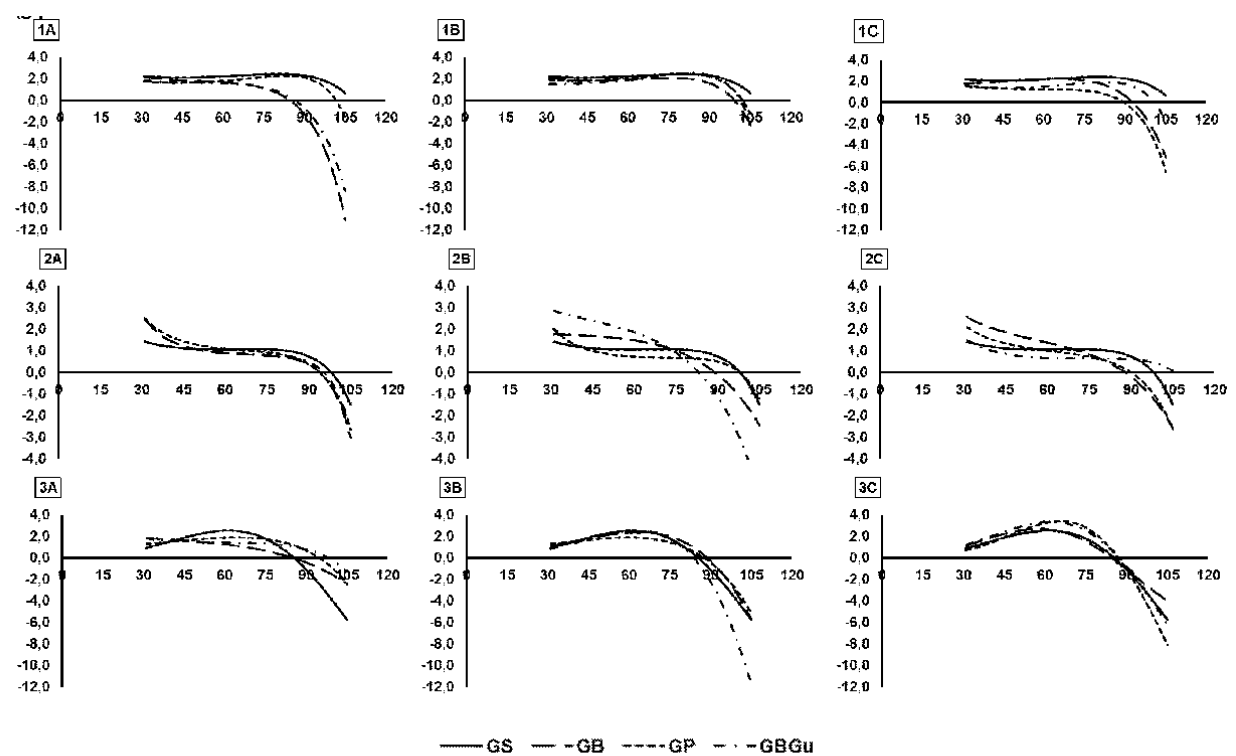

No ano 3 as plantas de girassol em cultivo solteiro e consorciado apresentaram um incremento na TAL, com valores máximos entre os 60 e 75 DAE para as três formas de semeadura. A partir daí observa-se uma queda chegando a valores negativos no final do ciclo 
(Figura 3.3A, 3.3B E 3.3C). Esta tendência foi verificada por Souza et al. (2013) trabalhando com girassol no Recôncavo Baiano, porém esses autores encontraram máximos valores de TAL aos 36 DAE.

Observa-se na Figura 3 diferenças nas curvas da TAL dos consórcios e do cultivo solteiro em relação aos três anos de estudo. Isso pode ser explicado pelo efeito dos fatores ambientais sobre a planta, principalmente a influência da precipitação que afetou diretamente o padrão de crescimento, o qual é reflexo dos processos metabólicos primários fotossíntese e respiração.

Os consórcios em SD e SSH no segundo ano agrícola apresentaram diferenças de incremento da TAL aos 45 e $60 \mathrm{DAE}$, sendo que os maiores valores foram na SD para os consórcios GB e GBGu e na SSH o consórcio GB (Figura 3.1B e 3.1C).

Figura 4 - Taxa assimilatória líquida (TAL) em dias após a emergência (DAE) de plantas de girassol submetidas a diferentes formas de semeaduras (semeadura simultânea, semeadura defasada e semeadura simultânea com aplicação de herbicida/graminicida) dos consórcios ( $\mathrm{A}=\mathrm{GB}=$ girassol + Urochloa ruziziensis (braquiária), $\mathrm{B}=\mathrm{GP}=$ girassol + Panicum maximum $\mathrm{cv}$. Tanzânia e C=GBGu=girassol + Urochloa ruziziensis $)$ + Cajanus cajan), em três anos agrícolas. Cruz das Almas - BA, 2020.
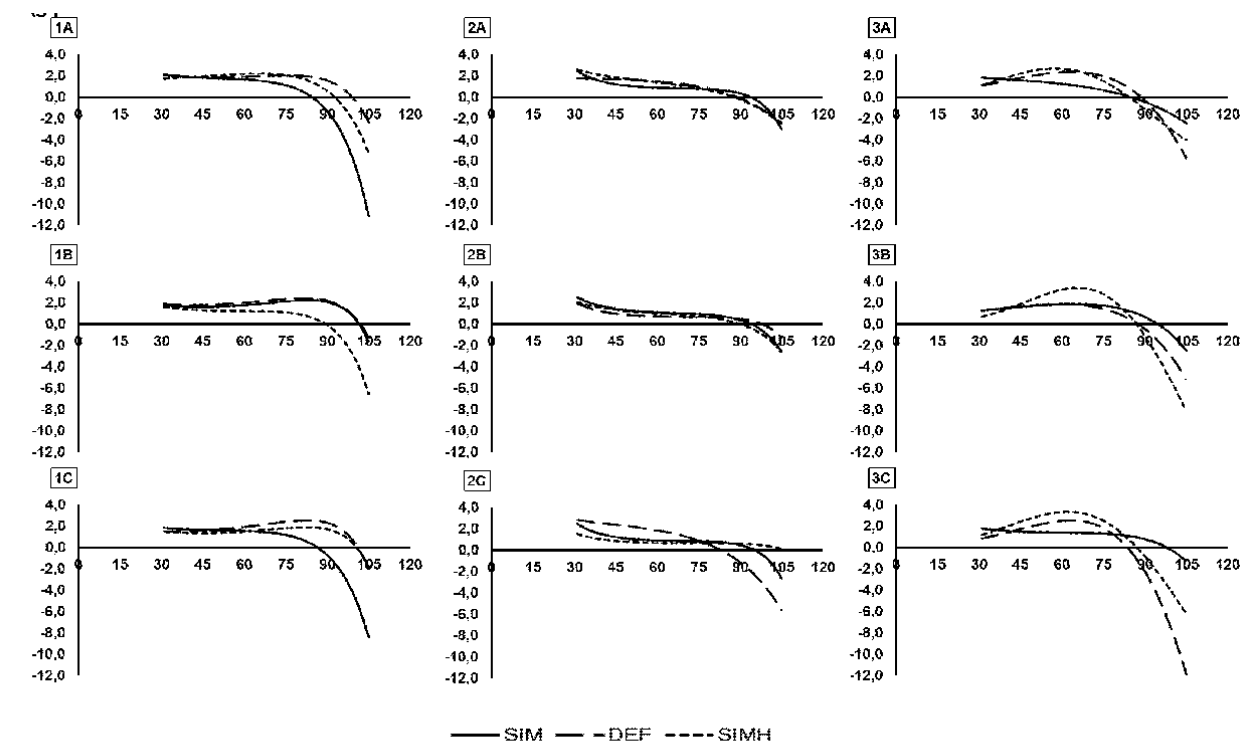

Comparando as formas de semeadura, nos anos 1 e 3, foi possível observar que ocorre uma queda na TAL antes de atingir os $90 \mathrm{DAE}$ para os consórcios submetidos a SS principalmente os consórcios GB e GBGu (Figura 4.1A, 4.1B e 4.1C e, 4.3A, 4.3B e 4.3C respectivamente). Enquanto que as SD e SSH retardaram um pouco mais essa queda na TAL.

A razão de área foliar (RAF) é um índice que representa a área foliar útil da planta. Considerado um componente morfofisiológico por corresponder a razão entre a área foliar 
(responsável pela captação de energia luminosa e $\mathrm{CO}_{2}$ na fotossíntese) e a massa da matéria seca total da planta. Varia com área foliar específica que é o componente morfológico e a razão de massa de folha que se constitui no componente fisiológico.

Nas Figuras 5 e 6 estão representadas a variação da RAF nos dias após a emergência do girassol em cultivo solteiro e consorciado com forrageiras (Figura 5), em diferentes formas de semeadura (Figura 6), em três anos agrícolas.

Nota-se nas curvas da RAF uma tendência de queda, a partir dos 30 DAE até atingir valor constante próximo a zero a partir dos 75 DAE. A RAF é uma taxa que reduz com o avanço do desenvolvimento vegetal, devido principalmente ao autosombreamento, com a tendência da diminuição da área foliar útil ou fotossinteticamente ativa para a produção de matéria seca.

No primeiro ano (Figura 5.1A, 5.1B e 5.1C) o girassol consorciado com as diferentes forrageiras apresentou maiores valores de RAF que o GS. Já para o ano 2, principalmente no período de 30 aos $45 \mathrm{DAE}$, o GS foi o que apresentou os maiores valores da RAF em relação aos consórcios (Figura 5.2A, 5.2B e 5.2C). Pode-se observar ainda, um pequeno aumento do girassol em consórcio, provavelmente, devido, a que nesta fase fenológica (45 a 60 DAE) a planta apresentava menor número de folhas o que levou a um menor autosombreamento. Ademais, o consórcio leva a planta do girassol uma competição interespecífica com as consortes.

Com o desenvolvimento da planta de girassol a RAF reflete a redução da capacidade fotossintética da planta em relação ao aumento da massa da matéria seca total. Os fotoassimilados, que na fase vegetativa era utilizado para a formação e expansão das folhas, a partir de determinado período, é realocado para a formação da inflorescência e enchimento dos grãos na fase reprodutiva da planta. Essa tendência de decréscimo na curva que representa a RAF também foi observada no estudo de diferentes culturas estudadas como girassol, mamão e soja (SOUZA et al., 2013; LIMA et al., 2007; CRUZ et al., 2011).

Figura 5 - Razão de área foliar (RAF) em dias após a emergência (DAE) de plantas de girassol submetidas a diferentes consórcios (GS=girassol solteiro, GB=girassol + Urochloa ruziziensis, $\mathrm{GP}=$ girassol + Panicum maximum cv. tanzânia, $\mathrm{GBGu}=$ girassol + Urochloa ruziziensis $)+$ Cajanus cajan) e formas de semeadura ( $\mathrm{A}=$ semeadura simultânea, $\mathrm{B}=$ semeadura defasada $\mathrm{e}$ $\mathrm{C}=$ semeadura simultânea com aplicação de herbicida/graminicida), em três anos agrícolas. Cruz das Almas - BA, 2020. 

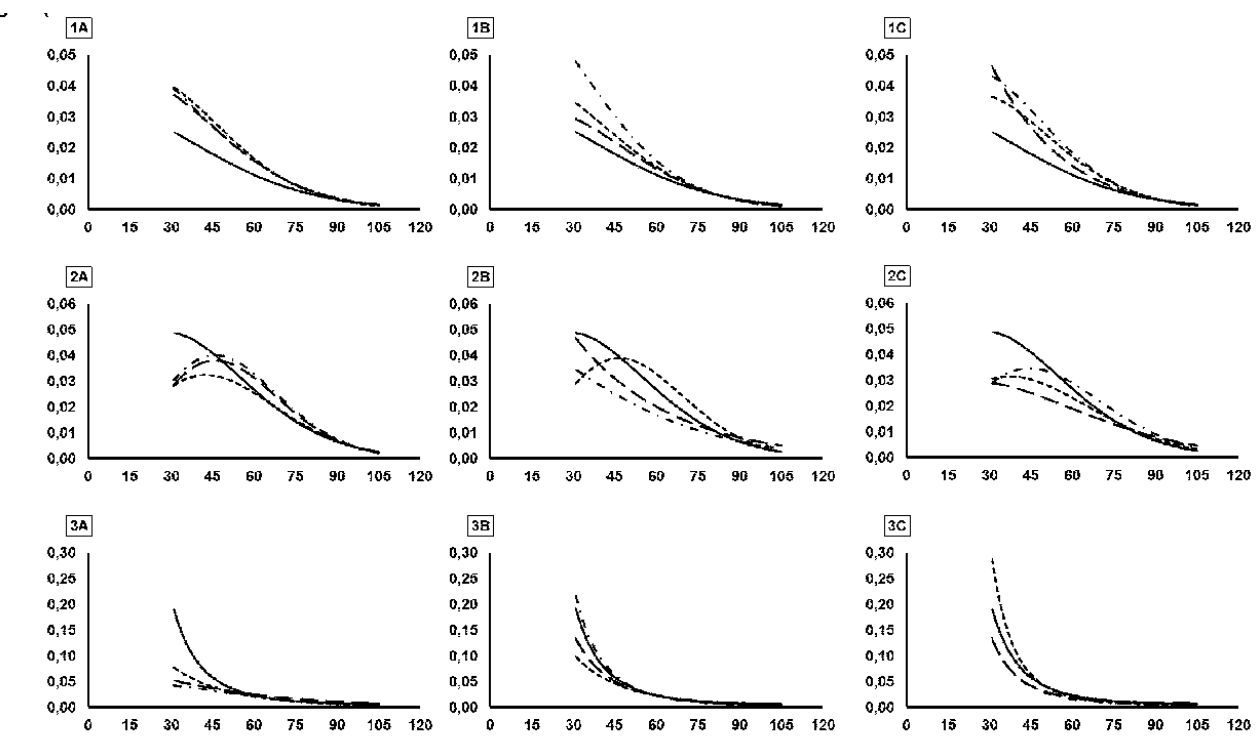

$-G S-G B-G-G P--G B G U$

Avaliando as formas de semeadura no terceiro ano (Figura 6.3A, 6.3B e 6.3C), foi possível observar que a SD e a SSH promoveram plantas de girassol com maiores taxas da RAF em relação a SS, podendo inferir que o girassol apresenta uma maior capacidade em competir com as forrageiras quando utilizado estes manejos como forma de suprimir a ação das forrageiras na taxa fotossintética do girassol.

Figura 6 - Razão de área foliar (RAF) em dias após a emergência (DAE) de plantas de girassol submetidas a diferentes formas de semeaduras (semeadura simultânea, semeadura defasada e semeadura simultânea com aplicação de herbicida/graminicida) dos consórcios ( $\mathrm{A}=\mathrm{GB}=$ girassol + Urochloa ruziziensis, $\mathrm{B}=\mathrm{GP}=$ girassol + Panicum maximum cv. Tanzânia e C=GBGu=girassol + Urochloa ruziziensis + Cajanus cajan), em três anos agrícolas. Cruz das Almas - BA, 2020. 

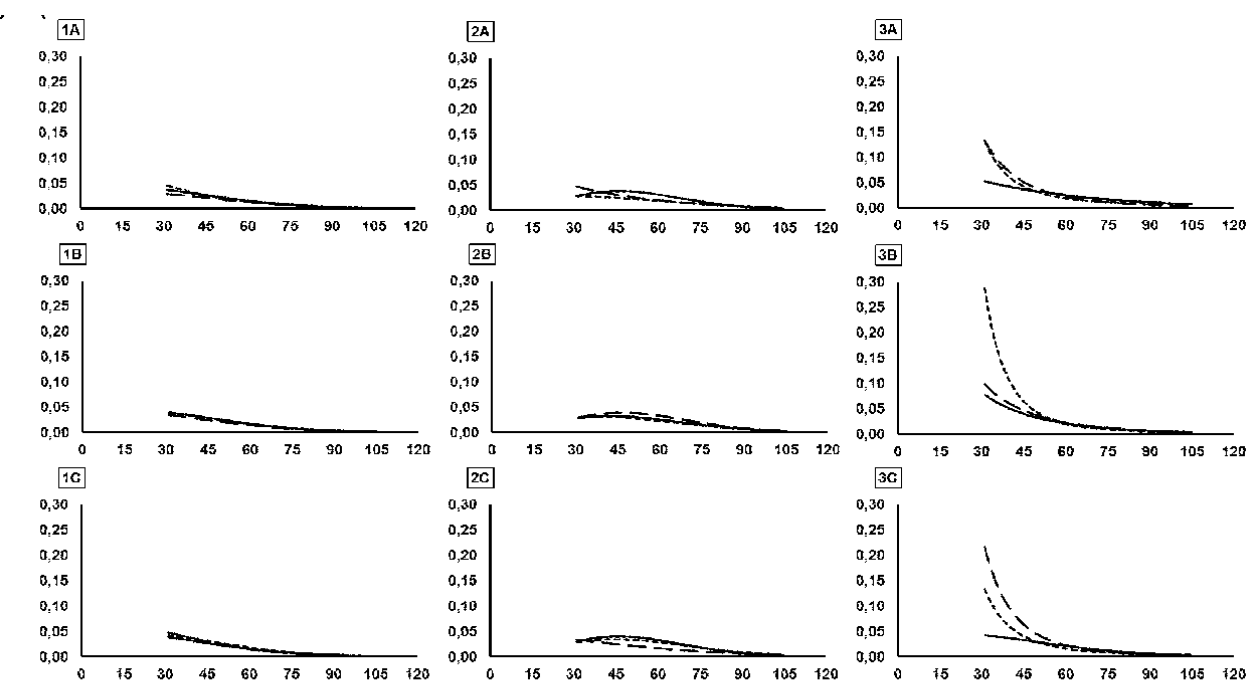

- SIN - DEF ----SIMH

O índice de área foliar (IAF) é definido pela relação entre a área foliar total e área do solo sombreada. Porém, segundo estudiosos, é um índice difícil de ser determinado devido a variação na projeção das folhas ao longo do dia. Então, como solução, determina-se o IAF a partir da relação da área foliar com a área de solo disponível para a planta, sendo considerado uma referência da superfície disponível para interceptação e absorção de luz, o qual pode variar com a população e distribuição de plantas.

Nas Figuras 7 e 8 estão representadas a variação do IAF nos dias após a emergência do girassol no cultivo solteiro e consorciado com forrageiras (Figura 7), em diferentes formas de semeadura (Figura 8), em três anos agrícolas.

Figura 7 - Índice de área foliar (IAF) em dias após a emergência (DAE) de plantas de girassol submetidas a diferentes consórcios (GS=girassol solteiro, $\mathrm{GB}=$ girassol + Urochloa ruziziensis,

GP=girassol + Panicum maximum cv. tanzânia, GBGu=girassol + Urochloa ruziziensis +

Cajanus cajan) e formas de semeadura ( $\mathrm{A}=$ semeadura simultânea, $\mathrm{B}=$ semeadura defasada $\mathrm{e}$ $\mathrm{C}=$ semeadura simultânea com aplicação de herbicida/graminicida), em três anos agrícolas. Cruz das Almas - BA, 2020. 

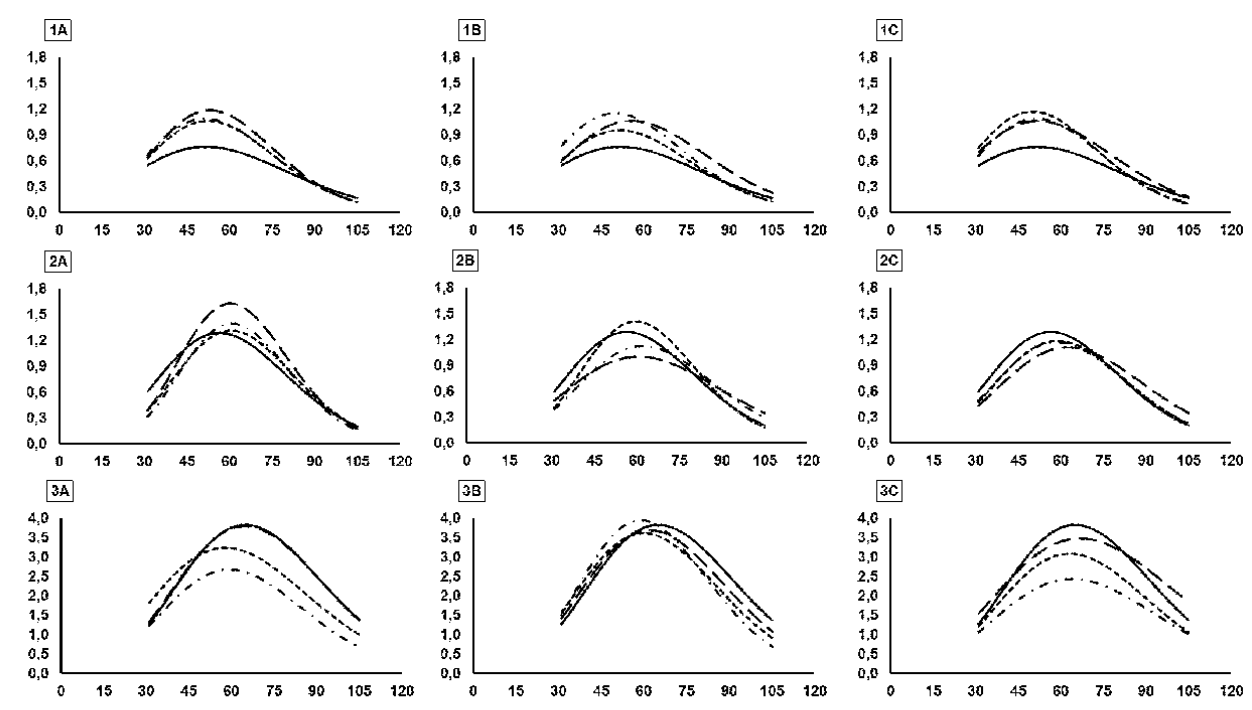

$-\mathrm{GS}-\mathrm{GB} \quad \cdots \mathrm{GP}-\cdot-\mathrm{GBG}$

Em ambas as figuras se observa que o IAF apresentou uma tendência parabólica esperada de crescimento, com pequenas variações nas curvas até atingir valores máximos entre os 45 e 75 DAE. Esses máximos valores foram dependentes da interação entre os fatores estudados, cultivo solteiro ou consorciado nas diferentes formas de semeadura e o ano agrícola (Figura 7). O conhecimento desta variação ao longo do ciclo do girassol permite inferir a capacidade ou velocidade da área foliar do vegetal cobrir a área do terreno disponível. Essa variação dos tratamentos em que o girassol foi submetido fica bem evidente aos 60 DAE.

Segundo Souza et al. (2013), a variação do IAF está diretamente relacionada com o estádio de desenvolvimento do girassol. Há um aumento rápido deste índice à medida que a planta cresce até a formação de flores e aquênios e decresce com senescência das folhas e final do ciclo da cultura. Estes autores encontraram valores máximos de IAF aos 51 DAE estudando a cultura no Recôncavo Baiano.

Figura 8 - Índice de área foliar (IAF) em dias após a emergência (DAE) de plantas de girassol submetidas a diferentes formas de semeaduras (semeadura simultânea, semeadura defasada e semeadura simultânea com aplicação de herbicida/graminicida) dos consórcios ( $\mathrm{A}=\mathrm{GB}=$ girassol + Urochloa ruziziensis, $\mathrm{B}=\mathrm{GP}=$ girassol + Panicum maximum $\mathrm{cv}$. Tanzânia e $\mathrm{C}=\mathrm{GBGu}=$ girassol + Urochloa ruziziensis + Cajanus cajan), em três anos agrícolas. Cruz das Almas - BA, 2020. 

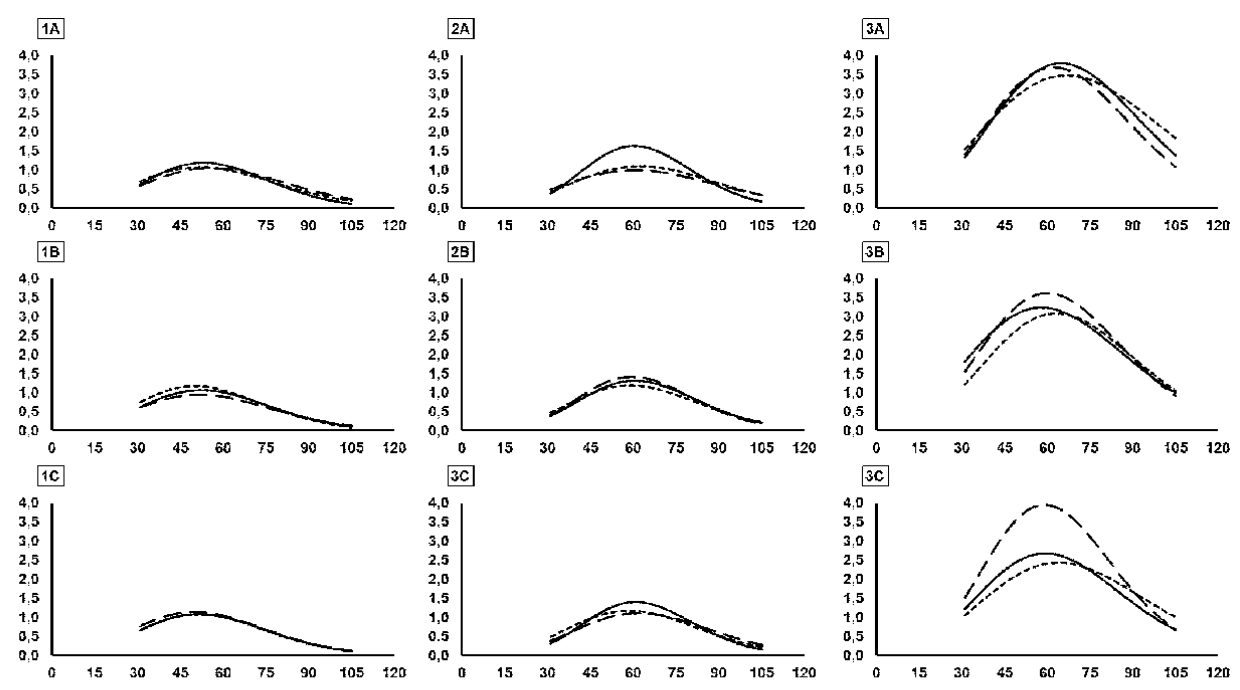

$-\operatorname{SiM}--D E F---S$ SIMH

Comparando os anos agrícolas, os valores mais elevados de IAF foram obtidos no terceiro ano (Figura 8) independente da forma de semeadura. Em comparação das formas de semeadura, a SSH no terceiro ano possibilitou que o girassol apresentasse maiores IAF, pois a aplicação do herbicida influenciou na menor competição da forrageira principalmente no consórcio triplo (Figura 8.3A, 8.3B e 8.3C).

De modo geral as plantas apresentam IAF máximo quando tem o máximo de área foliar cobrindo a área de terreno disponível para a planta, o que é típico de gramíneas em pastagens. É possível também que as plantas apresentem um IAF ótimo, que é alcançado quando a taxa de crescimento da cultura (TCC) é máxima, típico de cultivos. Neste estudo os IAF ótimos combinados com as TCC máximas estão representados na Tabela 2

A taxa de crescimento da cultura (TCC) é definida como o aumento em massa de matéria seca total da planta por unidade de tempo, que corresponde a um indicador da capacidade produtiva da planta, por meio da matéria seca acumulada.

Nas Figuras 9 e 10 estão representadas a variação da TCC nos dias após a emergência do girassol no cultivo solteiro e consorciado com forrageiras (Figura 9), em diferentes formas de semeadura (Figura 10), em três anos agrícolas.

As curvas de TCC (Figura 9) apresentaram um crescimento até atingirem valores máximos entre os 45 e 60 DAE para os anos 1 e 2 e, dos 60 aos 75 DAE no ano 3. As reduções das TCC acentuam-se aos 75 DAE para o girassol solteiro e consorciado. Este decréscimo no acúmulo de massa de matéria seca das plantas, até atingirem valores negativos, é resultado da paralização do crescimento vegetal com a maturação e a senescência das plantas, que chega a ser maior que o crescimento de novos tecidos. Curvas semelhantes foram encontradas por Machado 
et al. (2011) e Souza et al. (2013) trabalhando com a cultura do girassol submetidos a diferentes manejos.

Figura 9 - Taxa de crescimento da cultura (TCC) em dias após a emergência (DAE) de plantas de girassol submetidas a diferentes consórcios (GS=girassol solteiro, GB=girassol + Urochloa ruziziensis, GP=girassol + Panicum maximum cv. tanzânia, GBGu=girassol + Urochloa ruziziensis + Cajanus cajan $)$ e formas de semeadura $(\mathrm{A}=$ semeadura simultânea, $\mathrm{B}=$ semeadura defasada e $\mathrm{C}=$ semeadura simultânea com aplicação de herbicida/graminicida), em três anos agrícolas. Cruz das Almas - BA, 2020.
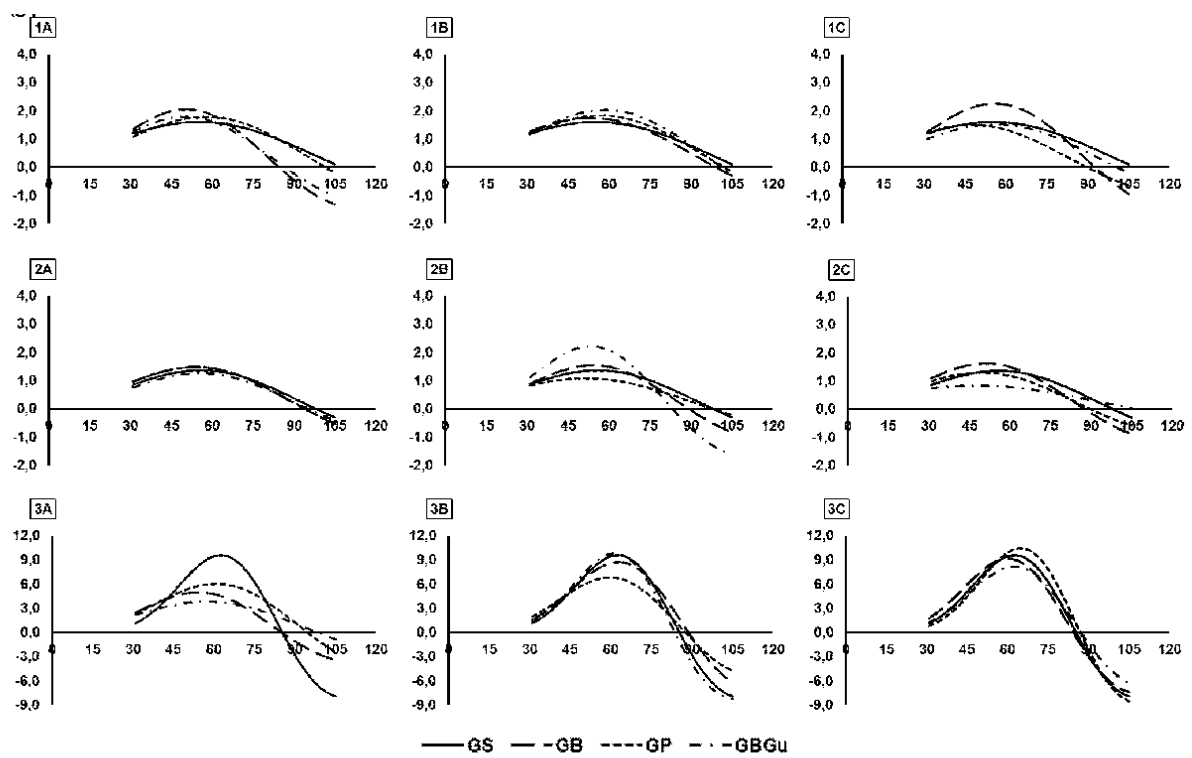

No terceiro, ao observar as tendências da TCC é possível verificar que os consórcios semeados simultaneamente com as forrageiras (Figura 9.3A) apresentaram menores acúmulos em relação ao cultivo solteiro, implicando a existência da competição das plantas consortes, o que não foi observado nas semeaduras defasadas e simultânea com aplicação do graminicida, em que o GS apresentou acúmulos próximos aos consórcios (Figura 9.3B e 9.3C).

Figura 10 - Taxa de crescimento da cultura (TCC) em dias após a emergência (DAE) de plantas de girassol submetidas a diferentes formas de semeaduras (semeadura simultânea, semeadura defasada e semeadura simultânea com aplicação de herbicida/graminicida) dos consórcios $(\mathrm{A}=\mathrm{GB}=$ girassol + Urochloa ruziziensis, $\mathrm{B}=\mathrm{GP}=$ girassol + Panicum maximum $\mathrm{cv}$. Tanzânia e $\mathrm{C}=\mathrm{GBGu}=$ girassol + Urochloa ruziziensis + Cajanus cajan), em três anos agrícolas. 

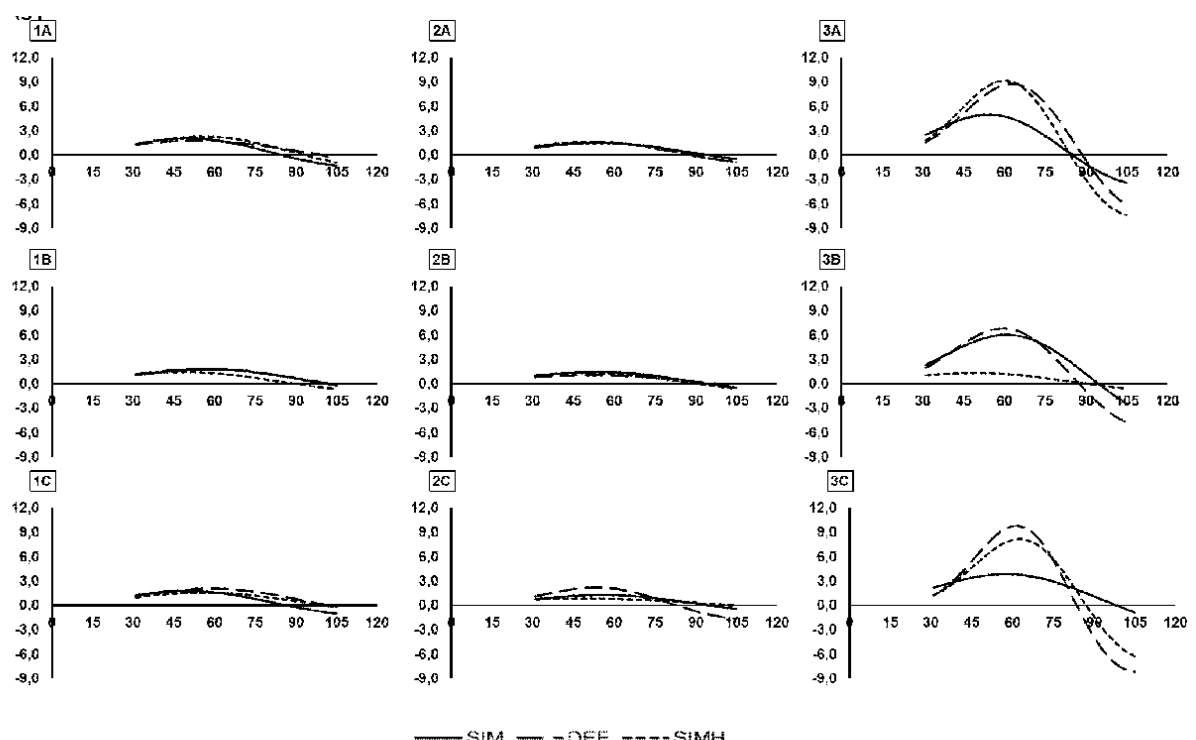

- $\operatorname{Sin}-$ - DEF -D-- SIMH

Para as formas de semeadura, nos anos 1 e 2 houve uma semelhança nos acúmulos de TCC para os diferentes consórcios. Já no ano 3 é possível observar que a SD e SSH promoveram maiores TCC, mostrando que as plantas de girassol foram favorecidas com o manejo de implantação do consórcio (Figura 10).

Como existe uma relação entre a máxima TCC e o valor do IAF para determiná-lo como ótimo, estão apresentados na Tabela 2 os valores máximos da TCC com seus respectivos DAE e o IAF máximo nos DAE e IAF ótimo relacionado as máximas TCC.

Tabela 2 - Valores máximos da taxa de crescimento da cultura (TCC) e máximo e ótimo para o índice de área foliar (IAF) com seus respectivos DAE observados nas plantas de girassol em cultivo solteiro (GS) e submetidas a diferentes consórcios (GB=girassol + Urochloa ruziziensis;

GP=girassol + Panicum maximum cv. Tanzânia e GBGu=girassol + Urochloa ruziziensis + Cajanus cajan) e formas de semeadura ( $\mathrm{SS}=$ semeadura simultânea, $\mathrm{SD}=$ semeadura defasada e SSH=semeadura simultânea com aplicação de herbicida/graminicida) em três anos agrícolas.

Cruz das Almas - BA, 2020.

\begin{tabular}{|c|c|c|c|c|c|c|c|c|}
\hline \multirow{2}{*}{ Ano } & \multirow{2}{*}{ Forma semeadura } & \multirow{2}{*}{ Consórcio } & \multicolumn{2}{|c|}{ TCC (g planta ${ }^{-1}$ dia $^{-1)}$} & \multicolumn{4}{|c|}{ IAF } \\
\hline & & & Máxima & DAE & Máximo & DAE & Ótimo & DAE \\
\hline \multirow{7}{*}{1} & & GS & 1,603 & 55 & 0,75763 & 52 & 0,7519 & 55 \\
\hline & & GB & 2,043 & 51 & 1,18524 & 53 & 1,17973 & 51 \\
\hline & SS & GP & 1,792 & 58 & 1,06443 & 52 & 1,06443 & 58 \\
\hline & & $\mathrm{GBGu}$ & 1,778 & 50 & 1,0917 & 51 & 1,08992 & 50 \\
\hline & & GB & 1,738 & 53 & 1,061 & 56 & 1,05467 & 53 \\
\hline & SD & GP & 1,83 & 57 & 0,94862 & 52 & 0,92445 & 57 \\
\hline & & $\mathrm{GBGu}$ & 2,021 & 59 & 1,14761 & 50 & 1,06435 & 59 \\
\hline
\end{tabular}




\begin{tabular}{|c|c|c|c|c|c|c|c|}
\hline \multirow{3}{*}{ SSH } & GB & 2,245 & 56 & 1,06378 & 52 & 1,04988 & 56 \\
\hline & GP & 1,493 & 47 & 1,17209 & 50 & 1,16068 & 47 \\
\hline & $\mathrm{GBGu}$ & 1,524 & 56 & 1,08628 & 51 & 1,06289 & 56 \\
\hline \multirow{4}{*}{ SS } & GS & 1,366 & 56 & 1,28343 & 56 & 1,28343 & 56 \\
\hline & GB & 1,475 & 54 & 1,62768 & 60 & 1,53891 & 54 \\
\hline & GP & 1,475 & 54 & 1,31594 & 61 & 1,25038 & 54 \\
\hline & $\mathrm{GBGu}$ & 1,266 & 56 & 1,39756 & 61 & 1,35248 & 56 \\
\hline \multirow{3}{*}{ SD } & GB & 1,546 & 54 & 0,99936 & 61 & 0,97072 & 54 \\
\hline & GP & 1,067 & 52 & 1,41042 & 60 & 1,30918 & 52 \\
\hline & GBGu & 2,212 & 53 & 1,12038 & 62 & 1,03895 & 53 \\
\hline \multirow{3}{*}{ SSH } & GB & 1,631 & 51 & 1,10567 & 62 & 0,99288 & 51 \\
\hline & GP & 1,306 & 49 & 1,18557 & 59 & 1,07266 & 49 \\
\hline & GBGu & 0,831 & 48 & 1,17022 & 58 & 1,04825 & 48 \\
\hline & GS & 9,589 & 63 & 3,82272 & 65 & 3,81106 & 63 \\
\hline & GB & 4,928 & 54 & 3,80255 & 65 & 3,47424 & 54 \\
\hline SS & GP & 6,053 & 61 & 3,2336 & 58 & 3,21334 & 61 \\
\hline & GBGu & 3,815 & 58 & 2,684 & 59 & 2,68086 & 58 \\
\hline & GB & 8,739 & 63 & 3,68649 & 62 & 3,68421 & 63 \\
\hline SD & GP & 6,819 & 60 & 3,61273 & 60 & 3,61273 & 60 \\
\hline & GBGu & 9,785 & 61 & 3,95828 & 59 & 3,94101 & 61 \\
\hline & GB & 9,109 & 60 & 3,47384 & 67 & 3,39454 & 60 \\
\hline SSH & GP & 10,454 & 65 & 3,08785 & 63 & 3,07942 & 65 \\
\hline & GBGu & 8,143 & 63 & 2,4368 & 64 & 2,43573 & 63 \\
\hline
\end{tabular}

Como pode ser observado, houve uma antecipação nos DAE em que as plantas de girassol apresentaram as máximas TCC nos dois primeiros anos em relação ao terceiro ano (Tabela 2).

No ano 3 o girassol apresentou maior TCC quando em consórcio com o capim Tanzânia em SSH como demonstrado na Tabela 2, verificando-se uma TCC máxima de 10,454 g planta ${ }^{-1}$ $\mathrm{dia}^{-1}$ aos 65 DAE. As plantas em cultivo solteiro alcançaram um TCC máximo de 9,589 g planta ${ }^{-}$ ${ }^{1} \mathrm{dia}^{-1}$ aos 63 DAE. Nesta pesquisa, no ano mais favorável ao desenvolvimento do girassol (3), os valores de TCC foram superiores aos observados por Machado et al. (2011) e Santos (2013).

Com as maiores TCC em cada ano agrícola obteve-se um IAF ótimo de 1,049 para o consórcio GB em SSH para o ano 1, 1,038 para o GBGu em SD para o ano 2 e, no ano 3 o valor de 3,079 para o consórcio GP em SSH (Tabela 2).

\section{CONCLUSÕES}

Os índices fisiológicos nos diferentes consórcios e formas de semeadura possibilitam identificar diferenças no crescimento de plantas do girassol e indica que os consórcios favorecem o desempenho vegetativo e produtivo da planta, em relação ao cultivo solteiro, principalmente em semeaduras defasadas e simultânea com aplicação de herbicida/graminicida. 
O girassol obteve maior desempenho nos consórcios girassol + Urochloa ruziziensis e girassol + Urochloa ruziziensis + Cajanus cajan devido às maiores TAL, IAF e TCC que constituem indicativos de maiores acúmulos de matéria seca, o que poderá resultar em maiores produtividades.

\section{REFERÊNCIAS}

BALBINO, L. C. et al. Evolução tecnológica e arranjos produtivos de sistemas de integração lavoura-pecuária-floresta no Brasil. Pesquisa Agropecuária Brasileira, Brasilia, v. 46, n. 10, 2011.

BRIGHENTI, A. M. et al. Integração lavoura-pecuária: a cultura do girassol consorciado com Brachiaria ruziziensis. EMBRAPA, Juiz de Fora, 2008, 12p. (Circular Técnica 96).

BRIGHENTI, A. M. et al. Girassol clearfield consorciado com Brachiaria ruziziensis utilizando doses reduzidas de herbicidas inibidores de ACCase. Embrapa Clima temperado, [S.L], abr. 2009. Disponível em:

<http://ainfo.cnptia.embrapa.br/digital/bitstream/item/34720/1/29859.pdf>. Acesso em: 09 dez. 2020.

COSTA, N. R. et al. Atributos do solo e acúmulo de carbono na integração lavourapecuária em sistema plantio direto. Revista Brasileira de Ciência do Solo, Viçosa, v. 39, n. 3, p. 852-863, 2015.

CRUZ, T. V. et al. Índices fisiológicos de cultivares de soja em diferentes épocas de semeadura no Oeste da Bahia. Enciclopédia Biosfera, Goiânia, vol.7, n. 13, p.663-679, 2011.

FERREIRA, L. R. et al. Formação de pastagens em sistemas de integração. Informe Agropecuário, Belo Horizonte, v. 28, n. 240, p. 52-62, 2007.

GIMENES, M. J. et al. Integração lavoura pecuária - Breve revisão. Revista Trópica Ciências Agrárias e Biológicas. V.4, n.1, p.52, 2010.

LIMA, J. F.; PEIXOTO, C. P.; LEDO, C. A. S. Índices fisiológicos e crescimento inicial de mamoeiro (Carica papaya L.) em casa de vegetação. Ciência e Agrotecnologia, Lavras, v. 31, n. 5, p. 1358-1363, 2007.

LOSS, A. et al. Agregação, carbono e nitrogênio em agregados do solo sob plantio direto com integração lavoura-pecuária. Pesquisa Agropecuária Brasileira, Brasilia, v. 46, n. 10, p. 1269-1266, 2011.

MACEDO, M. C. M. Integração lavoura e pecuária: o estado da arte e inovações tecnológicas. Revista Brasileira de Zootecnia, Viçosa, v. 38, p. 133-146, 2009.

MACHADO, G. S. et al. Crescimento de híbridos de girassol em sistema plantio direto no Recôncavo da Bahia. Enciclopédia Biosfera, Goiânia, v. 7, n. 13, p. 276-285, 2011. 
MENDONÇA, A. V. R.; SANTOS, J. P. A.; VERDE, D. dos S. V.; SOUZA, M. O. de.; SOUZA, J. S. Production of seedlings of Psidium cauliflorum Landrum \& Sobrall.

Revista Caatinga, Mossoró, v. 33, n. 2, p. 433 - 445, 2020.

MORAES, J. C. et al. Desempenho fisiológico da mamoneira EBDA MPB01, sob a ação de dois herbicidas, em dois períodos de cultivo no recôncavo sul baiano. Revista Magistra, v. 26, n. 3, p. 337-346, 2014.

PEIXOTO, C. P.; CRUZ, T. V.; PEIXOTO, M. F. S. P. Análise do crescimento quantitativo de plantas: Conceitos e práticas. Enciclopédia Biosfera, Goiânia, v. 7, n. 13, p. 51-76, 2011.

PEIXOTO, C. P. Princípios de Fisiologia Vegetal: teoria e prática. 1 ed. Rio de Janeiro, RJ: Editora Pod, p.125-136, 2020.

RODRIGUES, M. G. F.; NACIF, P. G. S.; COSTA, O. V.; OLSZEVSKI, N. Solos e suas relações com as paisagens naturais no município de Cruz das Almas - BA. Revista de Biologia e Ciências da Terra, Campina Grande, v.9, n.2, p.193-205, 2009.

SANTOS, H.G. Sistema Brasileiro de Classificação de Solos. 3 ed. rev. ampl. Brasília: Embrapa Produção de informação; Rio de Janeiro: Embrapa Solos, 2013. 353 p.

SOUZA, L. H. B. D. et al. Índices fisiológicos de girassol em diferentes épocas de semeadura e densidade de plantas no Recôncavo da Bahia. Magistra, Cruz das Almas, v. 25 , n. 2, p. 94-108, 2013. 